\title{
A EDUCAÇÃO DO CAMPO E O ENSINO DE GEOGRAFIA: PERSPECTIVAS DO PROJETO EDUCAÇÃO DO CAMPO DE CANGUÇU/RS
}

The rural education and geography teaching: perspectives of the rural education of Canguçu/RS project

Educación del campo y enseñanza de geografía: Perspectivas del proyecto de educación del campo de Canguçu/RS

\author{
Queli Rejane da Silva Konzgen* \\ Janete Webler Cancelier** \\ Juliane Paprosqui Marchi da Silva*** \\ * Universidade Federal de Santa Maria (UFSM) \\ E-mail: queliufpel@gmail.com \\ ** Doutora em Geografia (UFSM) \\ E-mail: janetewc@gmail.com \\ *** Universidade Federal de Santa Maria (UFSM) \\ E-mail: juliane_paprosqui@hotmail.com
}

\begin{abstract}
Resumo:
O artigo tem como objetivo compreender e apresentar as mudanças ocorridas no ensino de Geografia nas escolas de ensino fundamental do Município de Canguçu/RS, a partir da implantação do Projeto Educação do Campo de Canguçu/RS (EDUCCAN). O referido projeto busca implementar práticas didáticas e pedagógicas e projetos em consonância ao contexto social do campo em que o município está inserido. A pesquisa se caracteriza pela abordagem qualitativa e está organizada em um conjunto de procedimentos metodológicos. As referências teóricas estão centradas na compreensão das temáticas referentes à educação do campo e ao ensino de geografia. A caracterização geral da realidade escolar do município de Canguçu ocorreu através da sistematização de dados primários e secundários. Foram analisados os dados obtidos na entrevista com a coordenadora das escolas do campo de Canguçu, na aplicação de questionários com diretores e professoras de Geografia que atuam nas escolas que fazem parte do EDUCCAN. Os resultados demonstram que com a implantação do EDUCCAN ocorreu a valorização da comunidade local e do espaço rural, com isso, os conteúdos de Geografia passaram a ser contextualizados de acordo com a realidade do espaço escolar em que os alunos se encontram, bem como, a inserção de projetos vinculando temas geográficos aos conhecimentos da educação do campo. Ainda, ocorreram mudanças na rotina escolar com a inserção do turno integral, a criação de salas temáticas, a implantação de períodos destinados a Construção Pedagógica do Aluno (CPA) e a Construção Pedagógica do Professor (CPP).
\end{abstract}

Palavras-chave: Educação do Campo. Projeto EDUCCAN. Ensino de Geografia. Contexto Social. 


\begin{abstract}
:
The paper aims to comprehend and present the changes that occured in geography teaching in elementary schools in the municipality of Canguçu/RS, from the implementation of the Rural Education of Canguçu/RS Project (EDUCCAN). The referred project seeks to implement didatics and pedagogical practicies and projects in the line with the rural social context that the municipality is inserted. The research is characterized by the qualitative approach and is organized in a set of methodological procedures. The theoretical references are centered on the comprehension of rural education and geography teaching. The general description of the scholar reality in Canguçu occured through the systematization of primary and secondary data. The data obtained in the interview with the coordinator of field schools of Canguçu were collected and analyzed, in the application of questionnaires with principals and Geography teachers who work in schools that are part of EDUCCAN. The results show that with the implementation of EDUCCAN, the local community and the rural space were valued and, with this, the Geography studies started to be contextualized according to the scholar space reality in which the students are, as well as the insertion of projects linking geographic themes to the knowledge of field education. Still, changes in the school routine happened with the insertion of the full shift, the creation of thematic rooms, the implementation of periods for the Student Pedagogical Construction (CPA) and the Professor Pedagogical Construction (CPP).
\end{abstract}

Keywords: Rural Education. EDUCCAN Project. Geography Teaching. Social Context.

\title{
Resumen:
}

El artículo tiene como objetivo comprender y presentar los cambios que ocurrieron en la enseñanza de la geografía en escuelas primarias del Municipio de Canguçu/RS, desde la implementación del Proyecto de Educación del Campo de Canguçu/RS (EDUCCAN). El proyecto busca implementar prácticas y proyectos didácticos, pedagógicos de acuerdo con el contexto social del campo donde se inserta el municipio. La investigación se caracteriza por el enfoque cualitativo y se organiza en un conjunto de procedimientos metodológicos. Las referencias teóricas se centran en la comprensión del tema relacionado con la educación del campo y la enseñanza de la geografía. La caracterización general de la realidad escolar en el municipio de Canguçu se produjo a través de la sistematización de datos primarios y secundarios. Se analizaron los datos obtenidos en la entrevista con la coordinadora de las escuelas del campo de Canguçu, en la aplicación de cuestionarios con directores y profesores de Geografía que trabajan en escuelas que forman parte del proyecto EDUCCAN. Los resultados demuestran que con la implementación del EDUCCAN, se valoró la comunidad local y el espacio rural, con eso, los contenidos de Geografía comenzaron a contextualizarse de acuerdo con la realidad del espacio escolar en el que los estudiantes se encuentran, así como la inserción de proyectos que incluyen temas geográficos para el conocimiento de la educación del campo. Aún así, hubo cambios en la rutina escolar con la inserción del turno completo, la creación de salas temáticas, la implementación de períodos para la Construcción pedagógica del estudiante (CPA) y la Construcción pedagógica del profesor (CPP).

Palabras clave: Educación del Campo. Proyecto EDUCCAN. Enseñanza de Geografía. Contexto Social. 


\section{Introdução}

Por meio desta pesquisa, analisam-se as mudanças ocorridas no ensino de geografia em escolas da rede municipal, a partir da implantação do Projeto Educação do Campo de Canguçu/RS (EDUCCAN). O referido Projeto foi inserido no município no ano de 2018 e tem como objetivos valorizar as vivências, os conhecimentos e o trabalho, a partir do meio em que os alunos estão inseridos, sendo mantido pelo Poder Público Municipal de Canguçu/RS.

O EDUCCAN cumpre a Emenda à Lei Orgânica Municipal № 08/2017, que visa a implantação gradativa de educação em turno integral no município. Além dos conteúdos que compõem o currículo e dos conhecimentos estarem vinculados ao meio em que os alunos vivem, os horários das atividades curriculares presenciais e a distância são adequados a realidade dos alunos e suas famílias.

O município de Canguçu, área da pesquisa, possui 35 escolas municipais, sendo que 25 destas estão localizadas no espaço rural, das quais oito fazem parte do Projeto pesquisado, sendo elas: E.M.E.F. Cristo Rei, E.M.E.F. São João Batista de La Salle, E.M.E.F. Guido Timm Venzke, E.M.E.F. Oscar Fonseca da Silva, E.M.E.F. Heitor Soares Ribeiro, E.M.E.F. Carlos Moreira, E.M.E.F. Dr. Jaime de Faria e E.M.E.F. Marechal Floriano. As primeiras cinco escolas citadas se inseriram no projeto no ano de 2018 e as três últimas no ano de 2019.

As escolas inseridas no Projeto possuem turmas da pré-escola ao 9a ano, funcionam em turno integral, de forma presencial, em quatro dias da semana e um dia a distância. As atividades iniciam às 08h30min finalizando às 15h30min. Neste período, as crianças recebem alimentos três vezes: quando chegam pela manhã, no almoço e antes de irem para casa. O período realizado a distância caracteriza-se pela Pedagogia da Alternância, na qual o educando coloca em prática, em sua propriedade ou no local onde reside, os conhecimentos adquiridos no tempo de escola. "A alternância é o período alternado de vivência e estudo na Escola, na Família e Comunidade. Nesse sentido a alternância passa a exercer uma função metodológica e pedagógica no processo formativo dos educandos" (JESUS, 2011, p. 9).

Desta forma, levando em consideração a relevância do Projeto proposto, no sentido de alterar a realidade para aqueles que vivem no campo, a presente pesquisa busca compreender quais mudanças ocorreram no ensino de geografia com a implantação do Projeto Educação do Campo de Canguçu/RS (EDUCCAN)? Cabe enfatizar que a pesquisa empiríca foi realizada somente nas escolas que participam do projeto.

\section{Desenvolvimento:}

Além da seção introdutória, o artigo está organizado nas seguintes partes: Caracterização da área da pesquisa e sua estrutura educacional; Metodologia; Educação do campo e o ensino de geografia; A rede municipal de educação de Canguçu/RS e o Projeto EDUCCAN; Perspectivas e limites do Projeto Educação do Campo de Canguçu/RS (EDUCCAN) e as mudanças no ensino de geografia; Considerações finais.

ParaOnde!?, Porto Alegre, v.14, n.1, p.31-54, 2020.http://seer.ufrgs.br/paraonde 


\subsection{Caracterização da área da pesquisa e sua estrutura educacional:}

O município de Canguçu está localizado na região fisiográfica da Serra do Sudeste, no Escudo Cristalino Sul-Riograndense (Mapa 1). Possui uma população de 56.045 mil habitantes, sendo que $63,02 \%$ desta população vive em áreas rurais e $36,98 \%$ nas áreas urbanas (IBGE, 2019).

\section{Mapa 1 - Mapa de localização do município de Canguçu/RS}

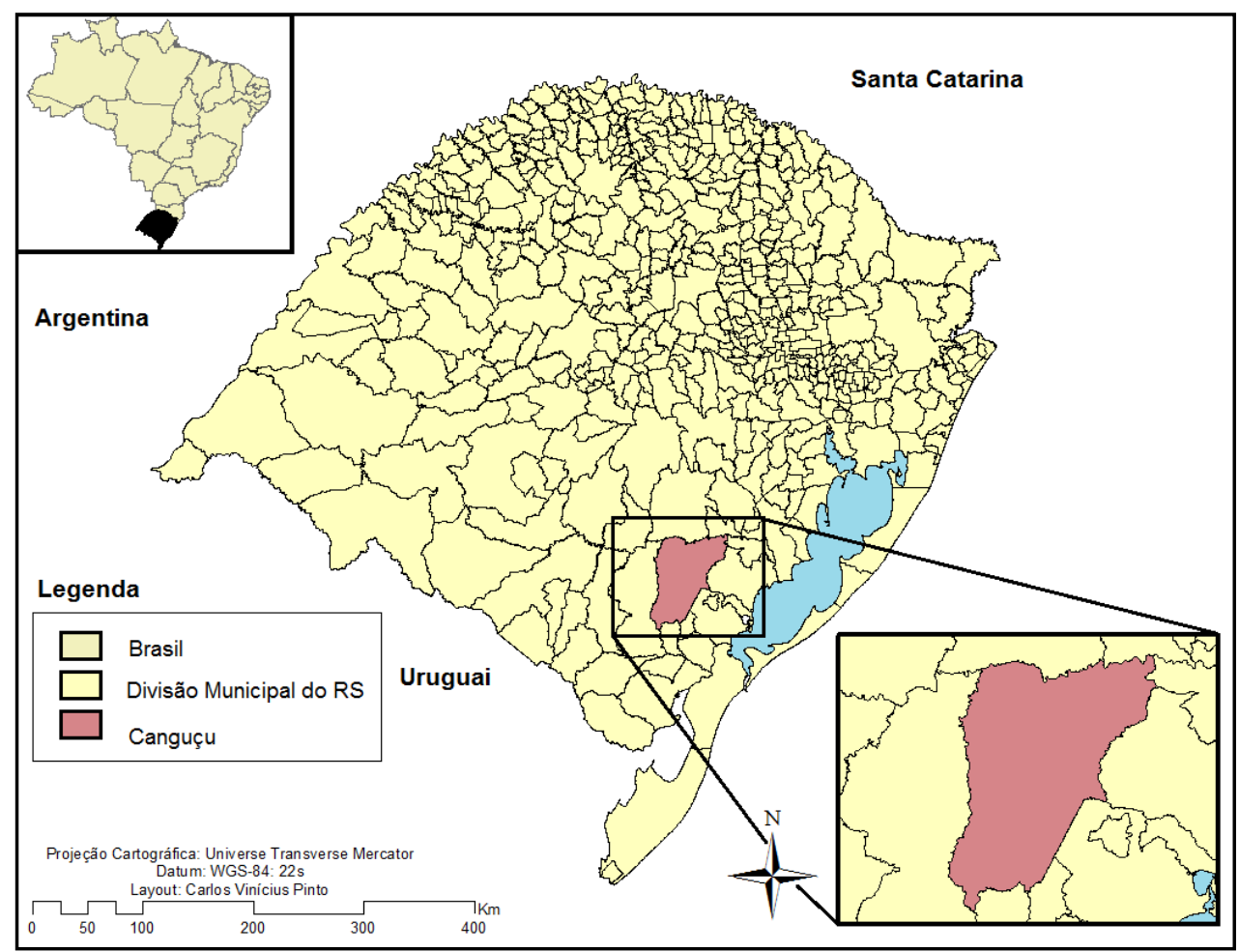

Fonte: Elaborado por Carlos Vinícius Pinto, 2019.

Sua configuração territorial está associada ao processo de ocupação e formação socioeconômica da região da Serra Sudeste do Rio Grande do Sul. Atualmente, em sua composição administrativa, o município é composto por cinco distritos, denominados como: $1^{\circ}, 2^{\circ}, 3^{\circ}, 4^{\circ}$ e $5^{\circ}$, sendo a sede localizada no $1^{\circ}$ distrito.

O município é conhecido como a Capital Nacional da Agricultura Familiar por possuir o maior número de pequenas propriedades do país. Canguçu é o maior produtor de tabaco do Brasil desde 2016. Um grande número de agricultores se dedica ao cultivo dessa cultura, por considerarem ser a mais viável economicamente e se adaptar às características da agricultura familiar do município. No ano de 2018, se caracterizou como a cultura predominante, com 5.432 famílias envolvidas na produção do mesmo (AFUBRA, 2018).

Dentro desta realidade geográfica, está inserida a estrutura educacional do município de Canguçu/RS, que é composta por 56 escolas. Desta totalidade, 35 são escolas municipais, 16 estaduais, 4 particulares e 1 Escola Família Agrícola da Região Sul (EFASUL). A maior parte dessas instituições está localizada no espaço rural, como pode ser observado na Tabela 1.

ParaOnde!?, Porto Alegre, v.14, n.1, p.31-54, 2020.http://seer.ufrgs.br/paraonde 
Tabela 1 - Estrutura educacional do município de Canguçu

\begin{tabular}{cccc}
\hline Escolas & Campo & Cidade & $\begin{array}{c}\text { Número Total de } \\
\text { Escolas }\end{array}$ \\
\hline Escolas Municipais & 25 & 10 & 35 \\
Escolas Estaduais & 12 & 04 & 16 \\
Escolas Particulares & - & 04 & 04 \\
EFASUL & - & 01 & 01 \\
\hline TOTAL & $\mathbf{3 7}$ & $\mathbf{1 9}$ & $\mathbf{5 6}$ \\
\hline
\end{tabular}

Fonte: Pesquisa de campo, 2019.

As escolas municipais são as que possuem o maior número de unidades presentes no espaço rural, totalizando em 25 escolas, que representam um percentual de $67,5 \%$ do total deste grupo. Essas ofertam modalidades de ensino que vão do infantil ao ensino fundamental completo, ocorrendo também a Educação de Jovens e Adultos (EJA). As escolas presentes no espaço urbano correspondem a 32,5\%.

No que tange às escolas da rede estadual de educação, estão presentes no município 16 escolas que ofertam modalidades de ensino do nível fundamental ao médio. Deste total, 12 escolas, ou seja, 75\% estão localizadas no espaço rural, das quais cinco se caracterizam pela oferta do ensino fundamental e médio e as demais apenas oferecem o ensino fundamental. As escolas localizadas no espaço urbano representam $25 \%$ do total deste grupo, sendo duas de ensino fundamental, uma com ensino fundamental e médio (Escola Estadual de Ensino Médio João de Deus Nunes), e a Escola Técnica Estadual Canguçu (ETEC) que oferta as modalidades de ensino médio e ensino médio integrado com possibilidade de curso técnico em agricultura ou contabilidade.

Por sua vez, as quatro escolas particulares, localizadas na área urbana, ofertam as modalidades de ensino que vão desde a educação infantil até o Curso Normal/Nível Médio, atendendo um total de 441 alunos, como pode ser observado na Tabela 2.

Tabela 2 - Informações gerais das escolas particulares de Canguçu

\begin{tabular}{|c|c|c|}
\hline Nome da Escola & Nível & Número de Alunos \\
\hline $\begin{array}{c}\text { Colégio Franciscano Nossa Senhora } \\
\text { Aparecida }\end{array}$ & $\begin{array}{l}\text { Educação Infantil, Ensino } \\
\text { Fundamental e Curso } \\
\text { Normal/Nível Médio. }\end{array}$ & 336 \\
\hline Escola de Educação Infantil Recrear & Educação Infantil. & 52 \\
\hline $\begin{array}{l}\text { Escola Luterana de Educação Infantil } \\
\text { São João }\end{array}$ & Educação Infantil. & 24 \\
\hline $\begin{array}{c}\text { Ser Criança - Centro de Educação } \\
\text { Infantil }\end{array}$ & Educação Infantil. & 29 \\
\hline TOTAL & & 441 \\
\hline
\end{tabular}

Pesquisa de campo, 2020.

Cabe ressaltar a presença, no município, desde o ano de 2016, da Escola Família Agrícola da Região Sul (EFASUL), a qual está situada no espaço urbano do referido município, localizada no Centro de Treinamento de Canguçu

ParaOnde!?, Porto Alegre, v.14, n.1, p.31-54, 2020.http://seer.ufrgs.br/paraonde 
(CETAC), dispondo de uma área física de 48,9 hectares. A EFASUL possui um total de 27 alunos e oferece de forma gratuita o Curso Técnico de Nível Médio Integrado e Subsequente em Agroecologia. Tal instituição realiza suas atividades didático-pedagógicas baseadas nos princípios da Educação do Campo, Agroecologia e Pedagogia da Alternância. Suas ações estão voltadas à formação de filhos(as) de agricultores familiares, dentre eles estão assentados de reforma agrária e quilombolas. A Escola não conta com recursos públicos ou privados regulares, o que faz com que suas atividades só se mantenham a partir do empenho coletivo de todos os envolvidos.

Cabe salientar, que as escolas particulares, as escolas estaduais e a EFASUL, foram inseridas neste trabalho somente para demonstrar a estrutura educacional presente no município estudado, não se caracterizando como foco da pesquisa.

\subsection{Metodologia}

A pesquisa caracteriza-se pela abordagem qualitativa. Foi realizada durante o ano de 2019 e início do ano de 2020, tendo como área de estudo o município de Canguçu/RS. Para seu desenvolvimento, utilizou-se a pesquisa teórica, documental, de campo e as análises. A pesquisa empírica foi realizada apenas com escolas municipais que fazem parte do Projeto EDUCCAN. Contudo, as demais escolas apresentadas foram inseridas, neste artigo, para demonstrar a estrutura educacional presente na área de pesquisa.

A pesquisa teórica e a organização teórico-conceitual permitiram compreender e apresentar discussões inerentes à educação do campo e ao ensino de geografia, bem como subsidiar a interpretação da realidade pesquisada.

Já a pesquisa documental, de fase exploratória, contou com 0 levantamento de dados empíricos junto ao Instituto Brasileiro de Geografia e Estatística (IBGE), na Secretaria Municipal de Educação, Esporte e Cultura de Canguçu e na Secretaria de Educação do Estado do Rio Grande do Sul da 5o Coordenadoria Regional de Educação (CRE) - Pelotas, escolas particulares e na EFASUL. Estas informações foram acessadas constantemente, paralelamente à pesquisa de campo e à pesquisa teórica. Permitindo a realização da caracterização geral da realidade escolar e da estrutura educacional do município de Canguçu.

Os dados qualitativos foram obtidos por meio da realização de uma entrevista semiestruturada e a aplicação de questionários a sujeitos ligados diretamente à estrutura educacional do município no segundo semestre do ano de 2019. Objetivava-se realizar a pesquisa empírica com os diretores e professoras de Geografia das oito escolas municipais que participam do Projeto EDUCCAN, as quais compõem $100 \%$ do universo da pesquisa. Contudo, após contato inicial, momento no qual foi exclarecido os objetivos da pesquisa e a importância da participação, somente quatro diretores e três professoras aceitaram participar.

ParaOnde!?, Porto Alegre, v.14, n.1, p.31-54, 2020.http://seer.ufrgs.br/paraonde 
A entrevista foi realizada de forma presencial com a Coordenadora Municipal das Escolas do Campo de Canguçu/RS. O objetivo foi coletar dados referentes à realidade escolar do município, o número de escolas municipais, o número de alunos matriculados, conhecer e entender o que é o Projeto Educação do Campo de Canguçu implementado pelo município, o número de escolas que participam, assim como conseguir o contato dos diretores e professores de geografia das escolas em que o Projeto em questão está implementado. As informações possibilitaram um melhor entendimento do Projeto e dos procedimentos necessários para a aplicação dos questionários e também o conhecimento do número total de escolas municipais inseridas no Projeto naquele ano.

No que tange aos questionários, estes foram enviados via e-mail e WhatsApp, a oito diretores e sete professoras de geografia das escolas que fazem parte do Projeto. Este critério foi adotado pela dificuldade de conseguir marcar um horário para a aplicação dos questionários de forma presencial, tendo em vista a carga horária significativa de atividades que os mesmos possuem nas escolas em que atuam. Mediante esta circustância e para dar continuidade à pesquisa, optou-se por encaminhar os questionários de forma digital, não sendo realizada nenhuma observação nas escolas e nas aulas das professoras.

Do total de questionários enviados (15), retornaram quatro de diretores e três de professoras. Antes do envio dos questionários, foi realizado contato, via telefone, com todos os depoentes, momento no qual apresentamos a pesquisa e seus objetivos. Sequencialmente os contatos seguiram objetivando sanar dúvidas. Porém obtivemos o retorno de $50 \%$ dos diretores e $37,5 \%$ das professoras. Os diretores estão nomeados como D1, D2, D3 e D4, as professoras como P1, P2 e P3, desses, apenas P3 pertence a mesma escola de um dos diretores que respondeu o questionário. A aplicação dos questionários objetivou compreender as mudanças que ocorreram nas escolas ao implantarem o Projeto, bem como no ensino de geografia e as perspectivas e limites do projeto analisado.

Ainda que nem todos tenham concordado em participar da pesquisa, considera-se que os resultados apresentam um olhar sobre quais mudanças estão sendo realizadas na forma de ensinar a Geografia nas escolas da rede municipal que participam do EDUCCAN.

Os dados coletados foram tabulados e organizados na forma de quadros e textos, mantendo as falas dos sujeitos pesquisados. A metodologia adotada possibilitou a realização das diferentes etapas e a compreenção da realidade empírica pesquisada.

\subsection{Educação do campo e o ensino de geografia}

A escola do campo nasce pelas demandas dos movimentos camponeses na busca pela construção de uma política educacional para os acampamentos e assentamentos da Reforma Agrária. Essa interpretação é relevante na compreensão da realidade que envolve a escola do campo, que se encontra no processo de espacialização da luta camponesa. A Geografia, como disciplina

ParaOnde!?, Porto Alegre, v.14, n.1, p.31-54, 2020.http://seer.ufrgs.br/paraonde 
escolar, compreende processos que envolvem a relação campesinato, ensino de geografia e Reforma Agrária (OLIVEIRA, 2011).

\section{A escola do campo é:}

[...] aquela que trabalha os interesses, a política, a cultura e a economia dos diversos grupos de trabalhadores e trabalhadoras do campo, nas suas diversas formas de trabalho e de organização, na sua dimensão de permanente processo, produzindo valores, conhecimentos e tecnologias na perspectiva do desenvolvimento social e econômico igualitário desta população. A identificação política e a inserção geográfica na própria realidade cultural do campo são condições fundamentais de sua implementação (FERNANDES; CERIOLI; CALDART, 2011, p. 53).

Historicamente, a maioria das escolas situadas no campo, segundo Copatti e Callai (2018, p. 236), fundamentadas em Lima (2013, p. 610):

[...] foram pensadas a partir do modelo de educação implementado na cidade, desconsiderando as especificidades sociais, culturais, econômicas, políticas e ambientais do mundo rural. Parte desse processo está associada à perspectiva de negação do campo enquanto espaço de produção cultural, econômica e política, influenciado pelo capitalismo que insiste em compreender as comunidades rurais como espaço do atraso, subdesenvolvimento e de improdutividade.

A escola do campo é reflexo das políticas públicas de interesses hegemônicos, ligados ao processo de implantação do capitalismo no campo. As leis promulgadas no transcorrer da história brasileira sempre trataram de homogeneizar as escolas do campo e da cidade, visando atender o processo de industrialização (WIZNIEWSKY, 2010).

Complementando a discussão, Caldart (2011, p.151) salienta que, "no Brasil, toda vez que houve alguma sinalização de política educacional ou de projeto pedagógico específico, isto foi feito para o meio rural e poucas vezes com os sujeitos do campo". A autora ainda relata que "sucessivos governos, além de não reconhecer o povo do campo como sujeito da política e da pedagogia, tentaram sujeitá-lo a um tipo de educação domesticadora e atrelada a modelos econômicos perversos".

Molina (2011), por sua vez, especifica que:

A Educação do Campo se constitui a partir de uma contradição que é a própria contradição de classe no campo: existe uma incompatibilidade de origem entre a agricultura capitalista e a Educação do Campo, exatamente porque a primeira sobrevive da exclusão e morte dos camponeses, que são os sujeitos principais da segunda. Em nosso debate isto tem sido referido como a principal oposição com a educação rural ou para o meio rural, que historicamente tem sido o nome dado às iniciativas do Estado de pensar a educação da população trabalhadora do campo, de modo a escamotear esta contradição e fazê-la de objeto e instrumento executor de políticas e de modelos de agricultura pensados em outros lugares, e para atender a outros interesses que não os seus como grupo social, classe e pessoas (MOLINA, 2011, p 13).

ParaOnde!?, Porto Alegre, v.14, n.1, p.31-54, 2020.http://seer.ufrgs.br/paraonde 
Neste contexto, fica evidente que as políticas públicas adotadas vêm produzindo um campo com muitas desigualdades, um campo que não permite o acesso a um direito universal, tampouco o ensino para a população em seu espaço de vivência. Esse processo é resultante, de acordo com Caldart (2011), da visão que se tem do campo como sinônimo de atraso e desarticulado com o atual modelo de desenvolvimento, o que ocasiona reflexos negativos para a educação.

A educação ofertada aos povos do campo deve estar articulada ao espaço de vivência. De acordo com Caldart (2011, p. 149-150), deve ser uma educação que seja no e do campo, no: o povo tem direito a ser educado no lugar onde vive; do: o povo tem direito a uma educação pensada desde o seu lugar e com sua participação, vinculada à sua cultura e às suas necessidades humanas e sociais.

Dessa forma, o movimento pela educação do campo busca modificar a estrutura colocada, garantindo através da educação melhores condições de vida para os sujeitos do campo (CARDART, 2004). A escola ocupa um papel central nesse processo, contudo precisa desenvolver, como bem aponta Fernandes (2011), um projeto educativo contextualizado, que trabalhe a produção do conhecimento a partir de questões relevantes para intervenção social nesta realidade.

Quando falamos de educação do campo, segundo Fernandes (2014), estamos nos referindo aos territórios camponeses, que são criados por relações familiares, associativas e cooperativas, constituindo relações não capitalistas.

\footnotetext{
Todavia, quando os territórios das relações não capitalistas são apropriados pelas relações capitalistas, eles são subordinados e depois destruídos, por isso, precisamos pensar a emancipação dos territórios camponeses com uma educação do campo que promova o seu desenvolvimento. Esta educação precisa pensar a lógica territorial camponesa e o seu desenvolvimento. Assim, não podemos pensar numa educação para o assalariamento, mas em uma educação em todos os níveis e dimensões para o trabalho familiar (FERNANDES, 2014, p.3).
}

A educação do campo não busca somente oportunizar o acesso à educação, também procura enaltecer os conhecimentos das comunidades tradicionais a partir de seus saberes e práticas, de suas relações com a natureza e seus processos de produção, ou seja, uma educação voltada para a garantia do modo de vida do campesinato. Nesse sentido, é premissa básica desta modalidade educacional o consenso de que a educação dos povos do campo não pode acontecer pela simples transposição dos modelos educacionais urbanos para o espaço rural, por isso, é importante que novas matrizes pedagógicas se desenvolvam, para que os educadores do campo tenham uma formação que os aproxime da sua realidade.

ParaOnde!?, Porto Alegre, v.14, n.1, p.31-54, 2020.http://seer.ufrgs.br/paraonde 
Esta realidade pode se tornar possível a partir da inserção nos componentes curriculares das escolas do campo de temáticas vinculadas aos domínios da educação do campo. Considera-se como ponto de partida a elaboração do Projeto Político Pedagógico (PPP), embasando-o na realidade em que a escola está inserida. A partir do PPP, é possível trabalhar conteúdos relacionados à realidade, à vivência, ao trabalho e aos valores identitários da comunidade (MEDEIROS; FOGAÇA, 2016, p. 140).

A busca pela emancipação do sujeito do campo e pelo fortalecimento das escolas também perpassa pela consolidação e ampliação dos Cursos de Licenciatura em Educação do Campo, haja vista que nestas licenciaturas os futuros educadores são preparados para atuar em distintas realidades, nos mais diferentes contextos em que estão inseridos os sujeitos do campo.

No que tange à Geografia, cabe, antes de tudo, compreender que seu objeto de estudo é o espaço geográfico. Ensinar Geografia em uma escola do campo demanda pensar qual conhecimento geográfico se deseja produzir, quais são significativos para os sujeitos, quais práticas pedagógicas são possíveis de serem realizadas em atendimento ao contexto social do campo, bem como integrar a comunidade escolar para o resgate de tradições, conhecimentos e valores ampliando aprendizagens, atendendo também aos conceitos e enfoques que podem servir para a construção da aprendizagem de modo que a educação tenha significado para as crianças e jovens que vivem no campo.

Alinhada a este contexto, Wizniewsky (2010, p. 27-28) afirma que:

[...] o professor de geografia possui um duplo desafio: o primeiro se refere à ação educativa dos sujeitos do campo, centrado na construção do conhecimento, sendo a geografia um elo integrador no processo interdisciplinar; o segundo trata da significação do lugar, sem perder a relação com o global. É, portanto, cada vez mais necessário uma profunda reflexão nos cursos de licenciatura e, nesse caso, nos cursos de geografia, fazendo um acompanhamento do processo educativo nas escolas do campo, tanto na formação permanente de profissionais, como na realização de projetos de pesquisa e extensão, formas de proceder que aproximam o futuro docente em geografia de uma realidade, na maioria das vezes, esquecida nos currículos dos cursos de formação inicial de professores.

Associar o conhecimento teórico-metodológico da ciência geográfica e da geografia escolar ao contexto específico das comunidades do campo é considerado um desafio e uma necessidade para a afirmação destes povos, a manutenção de sua diversidade e a promoção da cidadania (COPATTI; CALLAI, 2018).

De acordo, ainda, com os apontamentos das autoras, a Geografia contribui na formação das crianças e jovens do campo, bem como na constituição de sujeitos conscientes e críticos, capazes de compreender 0 espaço onde vivem e suas relações com dimensões do espaço local e global.

A reflexão sobre a vivência e importância do campo enquanto lugar de vida e de reprodução social, econômica e cultural, torna-se possível a partir do

ParaOnde!?, Porto Alegre, v.14, n.1, p.31-54, 2020.http://seer.ufrgs.br/paraonde 
momento em que o professor de Geografia passa a ter conhecimentos sobre os processos históricos que possibilitaram a formação das escolas do campo, bem como a importância destas escolas na consolidação de uma sociedade igualitária. Neste contexto, o domínio do Projeto Político Pedagógico da escola e da realidade do âmbito escolar em que ela está inserida é essencial.

O ensino de Geografia na escola do campo se ressignifica quando o professor consegue estabelecer relações entre conteúdo, lugar de vida dos alunos e demais espaços, capacitando-o para as transformações. É necessário compreender como distintos fenômenos afetam e interferem nas dinâmicas locais e na vida de cada sujeito, sendo a interpretação da realidade, neste processo, essencial. Os alunos aprendem com base no que já conhecem, a interação entre conhecimento prévio e o novo possibilita a elaboração de um conhecimento processual e uma aprendizagem significativa.

Desta forma, o ensino de Geografia na escola do campo deve aproximar a noção de "lugar" de seus sujeitos, tendo em vista que no lugar estão materializadas distintas formas que caracterizam as paisagens e identificam os lugares muitas vezes como únicos. É fundamental que se busque reconhecer os vínculos afetivos que ligam as pessoas aos lugares (CALLAI, 2000).

O professor de Geografia possui importante papel como articulador da construção do conhecimento do lugar, e a Geografia deve dialogar com as demais disciplinas, em projetos que aproximem o sujeito do campo, sua comunidade e escola (WIZNIEWSKY, 2010).

Nos últimos 20 anos, as discussões teóricas e as pesquisas científicas vinculadas às temáticas de educação do campo vêm se ampliando de forma significativa. Autores e Movimentos Sociais procuram demonstrar a presença e importância destas escolas em distintas realidades, levando, inclusive, a discussão para o cenário político na busca pela consolidação de políticas que propiciem a continuidade destas escolas. Todo esse processo tem possibilitado a ampliação das legislações, como é o caso das Diretrizes Operacionais para Educação do Campo publicada em 2002 que, dentre outros elementos, traz a definição da identidade da Educação do Campo em seu Art. 2ํㅜ

A identidade da escola do campo é definida pela sua vinculação às questões inerentes à sua realidade, ancorando-se na temporalidade e saberes próprios dos estudantes, na memória coletiva que sinaliza futuros, na rede de ciência e tecnologia disponível na sociedade e nos movimentos sociais em defesa de projetos que associem as soluções exigidas por essas questões à qualidade social da vida coletiva no país (BRASIL, 2002).

Posteriormente, tem-se a Resolução CNE/CEB №. 2 de 2008, que estabelece diretrizes complementares, normas e princípios para 0 desenvolvimento de políticas públicas de atendimento a Educação Básica do Campo, complementando as Diretrizes Operacionais instituídas anteriormente. O Decreto Presidencial № 7352 de 04 de novembro de 2010, dispõe sobre a política de Educação do Campo e o PRONERA, definindo as características das escolas do campo, bem como o que é considerado como população do campo. Por fim, mas não menos importante, no Estado do Rio Grande do Sul

ParaOnde!?, Porto Alegre, v.14, n.1, p.31-54, 2020.http://seer.ufrgs.br/paraonde 
através do Parecer № 0002/2018 são definidas as Diretrizes Curriculares para a oferta da Educação do Campo no Sistema Estadual de Ensino dando origem à Resolução № 342, de 11 de abril de 2018. Resolução que estabelece condições para a oferta no Sistema Estadual de Ensino e caracteriza a educação do campo, conforme segue:

III - educação do campo: compreende a Educação Básica em níveis (Educação Infantil, Ensino Fundamental - anos iniciais e finais e Ensino Médio) e diferentes modalidades, a Educação de Jovens e Adultos, Educação Profissional e Tecnológica, destinando-se ao atendimento às populações do campo em suas mais variadas formas de reprodução da vida (Res. 342/2018, p.01).

Apesar de toda legislação evidenciar a necessidade de se pensar em uma educação do campo para o campo, cabe a cada escola - através de seu Projeto Político Pedagógico - articular em conjunto com a comunidade escolar, meios e estratégias de aproximação do currículo com o meio onde ela se insere. As competências docentes desempenham um papel fundamental, no sentido de buscar metodologias que possibilitem essa aproximação para que de fato a escola do campo seja para o campo e não descolada da realidade apenas como uma transposição das escolas urbanas.

Dentro desta perspectiva, destaca-se o município de Canguçu/RS, área de pesquisa, que vem desde o ano de 2018 ampliando o número de escolas do campo a partir da implementação do Projeto Educação do Campo de Canguçu/RS (EDUCCAN), como será apresentado sequencialmente.

\subsection{A rede municipal de educação de Canguçu/RS e o Projeto EDUCCAN}

Anteriormente, já se citou que estão presentes 35 escolas municipais em Canguçu, 25 localizadas no espaço rural, das quais oito fazem parte do Projeto Educação do Campo. No ano de 2019, o número total de alunos matriculados na rede municipal de educação foi de 5.345 alunos. Deste total, 2.950 são de escolas do espaço rural, desses, 1.175 alunos estão matriculados nas escolas que fazem parte do Projeto. Os demais, ou seja, 2.395 nas escolas do espaço urbano. O maior número de matrículas presentes em escolas do espaço rural é compreendido pela totalidade de população residente neste espaço ser correspondende a $63,2 \%$ da população total do município.

Toda esta estrutura educacional exige a presença de um expressivo quadro docente. Para atender a demanda, o município de Canguçu conta diretamente com 527 professores, entre os quais estão professores nomeados e contratados de forma temporária. Deste total, $77,2 \%$ trabalham nas escolas localizadas no espaço rural e $22,8 \%$ nas escolas do espaço urbano. O número total de professores municipais que atuam nas escolas do Projeto bem como 0 número de alunos pode ser visualizado a partir da Tabela 3.

ParaOnde!?, Porto Alegre, v.14, n.1, p.31-54, 2020.http://seer.ufrgs.br/paraonde 
Tabela 3 - Número de alunos e professores das escolas do campo

\begin{tabular}{ccc}
\hline Escolas & $\begin{array}{c}\text { Número de } \\
\text { Alunos }\end{array}$ & $\begin{array}{c}\text { Número de } \\
\text { Professores }\end{array}$ \\
\hline E. M. E. F. Carlos Moreira & 131 & 13 \\
E. M. E. F. Cristo Rei & 135 & 12 \\
E. M. E. F. Dr. Jaime de Faria & 84 & 11 \\
E. M. E. F. Guido Timm Venzke & 178 & 13 \\
E. M. E. F. Heitor Soares Ribeiro & 264 & 15 \\
E. M. E. F. São João Batista de La Salle & 79 & 09 \\
E. M. E. F. Marechal Floriano & 134 & 13 \\
E. M. E. F. Oscar Fonseca da Silva & 170 & 13 \\
\hline TOTAL & $\mathbf{1 . 1 7 5}$ & $\mathbf{9 9}$
\end{tabular}

Fonte: Pesquisa de campo, 2019.

O Projeto Educação do Campo implementado no município de Canguçu/RS foi elaborado tomando como referência as demandas previstas nas Diretrizes Operacionais da Educação do Campo, documento esse que prevê que o ensino deve estar articulado à realidade e ao espaço em que o aluno está inserido, o que exige dos docentes um conhecimento sobre o território em que as escolas estão inseridas.

As escolas pertencentes ao Projeto oferecem duas modalidades da Educação Básica: a Educação Infantil e Ensino Fundamental. Conforme o "Art. 25 - A Educação Infantil é destinada às crianças de 4 a 5 anos e 11 meses de idade [...]. Art. 27 - O Ensino Fundamental está organizado em nove anos, conforme legislação vigente, com regime de progressão anual" (REGIMENTO EDUCCAN, 2019, p. 17).

Em relação à distribuição da carga horária, o regimento do Projeto em seus parágrafos primeiro, segundo e terceiro apontam normas que devem ser seguidas no que se refere à carga horária semanal, anual e aos períodos letivos que devem ser cumpridos nas escolas.

A carga horária semanal é de $07 \mathrm{~h} \times 04$ dias $=28 \mathrm{~h}$ semanais (presenciais); $07 \mathrm{~h} \times 01$ dia $=07 \mathrm{~h}$ semanais (a distância), totalizando 35 horas semanais. A carga horária anual é de $35 \mathrm{~h}$ semanais $\times 04$ semanas $=140 \mathrm{~h}$ mensais; 10 meses $\times 140 \mathrm{~h}$ mensais $=1400 \mathrm{~h}$ anuais (1120h presencias e 280h a distância). Por sua vez, os sete períodos letivos diários possuem duração de 50 minutos (REGIMENTO EDUCCAN, 2019, p. 20). Vale ressaltar que o ano letivo tem duração de aproximadamente 10 meses, pois os outros dois meses compreendem o período de férias de verão e nesse espaço de 10 meses, temse as chamadas férias de inverno com duração de uma semana. A carga horária apresentada é válida tanto para a educação infantil quanto para 0 ensino fundamental.

Desta forma, são 200 dias letivos anuais, dos quais 160 dias ocorrem de forma presencial e 40 dias a distância. Nos dias letivos, além dos períodos normais, ainda estão presentes, durante a semana, 3 períodos extracurriculares, nos quais os professores trabalham projetos relacionados a realidade dos alunos, dentro da chamada Construção Pedagógica do Aluno

ParaOnde!?, Porto Alegre, v.14, n.1, p.31-54, 2020.http://seer.ufrgs.br/paraonde 
(CPA).

Além disso, o EDUCCAN possibilita horários para a Construção Pedagógica do Professor (CPP), que acontece todas as segundas-feiras, momento em que ocorre o planejamento das aulas, dos projetos, da aprendizagem e a troca de experiências entre professores. Neste tempo, os alunos estão em suas residências, realizando atividades à distância, aplicando os conhecimentos adquiridos em sala a partir das práticas desenvolvidas no decorrer do Projeto.

Em relação ao Projeto Político Pedagógico (PPP), o Regimento EDUCCAN (2019, p. 7), especifica que cada escola inserida no Projeto deverá elaborar seu PPP de acordo com a realidade que está inserida, regulamentado com base no Regimento da Educação Municipal e amparado na legislação vigente. O mesmo será posteriormente avaliado e deverá ser aprovado pela Secretaria Municipal de Educação, processo realizado pelas oito escolas que atualmente compõem o Projeto.

$\mathrm{Na}$ entrevista realizada com a Coordenadora das Escolas do Campo de Canguçu, a mesma, evidenciou que muitos são os avanços conquistados com o Projeto EDUCCAN, entre os quais destaca o desenvolvimento de conteúdos e projetos vinculados às comunidades em que os alunos estão inseridos e , tendo em vista que a maior parte deles são filhos de agricultores familiares, as temáticas buscam ser trabalhadas no sentido de propiciar a permanência dos jovens no campo, almejando incentivar a sucessão rural nas propriedades (DIÁRIO DE CAMPO, 2019).

Porém, a depoente ainda relatou que a falta de professores qualificados para trabalhar em escolas do campo e que compreendam suas especificidades, é um agravante presente. Em tais escolas, pelas suas características não é possível reproduzir os conteúdos das escolas urbanas (DIÁRIO DE CAMPO, 2019). Neste processo, a prefeitura busca qualificar seus professores, a partir de Construção Pedagógica do Professor e na oferta de cursos de formação continuada.

A verificação - a fim de conferir se as metas e objetivos do EDUCCAN estão sendo alcançados nas escolas - é realizada através de reuniões periódicas entre a Secretaria Municipal de Educação com professores, coordenadores e diretores das escolas. Também são realizadas reuniões com a presença da comunidade escolar. Contudo, o Projeto está em fase inicial, tendo em vista que começou no ano de 2018, com isso, a entrevistada relatou que irão perceber os resultados a longo prazo (DIÁRIO DE CAMPO, 2019).

A partir do Mapa 2, é possível visualizar a localização das escolas que participam do EDUCCAN. Do total, quatro (1, 6, 7 e 8), estão inseridas no primeiro distrito, sendo este o distrito da sede urbana municipal. Também é percebível no mapa, a existência de duas escolas no $2^{\circ}$ distrito (4 e 5), uma escola no $5^{\circ}$ distrito (2), uma no $4^{\circ}$ distrito (3) e nenhuma escola no $3^{\circ}$ distrito.

Cabe destacar que a inexistência de escolas no $3^{\circ}$ distrito, até 0 momento em que a pesquisa foi realizada, segundo semestre do ano de 2019, decorre por não ter havido interesse das escolas localizadas no referido espaço em participar do Projeto. A adesão das escolas municipais ocorre de forma

ParaOnde!?, Porto Alegre, v.14, n.1, p.31-54, 2020.http://seer.ufrgs.br/paraonde 
voluntária, não sendo obrigatória. Assim, as que possuem interesse se inscrevem na Secretaria Municipal de Educação, a qual impõe a adesão ao atendimento simultâneo dois critérios: $1^{\circ}$ ) Infraestrutura da escola; $2^{\circ}$ ): 0 interesse da comunidade escolar e dos professores da escola.

\section{Mapa 2 - Mapa de localização das escolas que compõem a Educação do Campo de Canguçu}
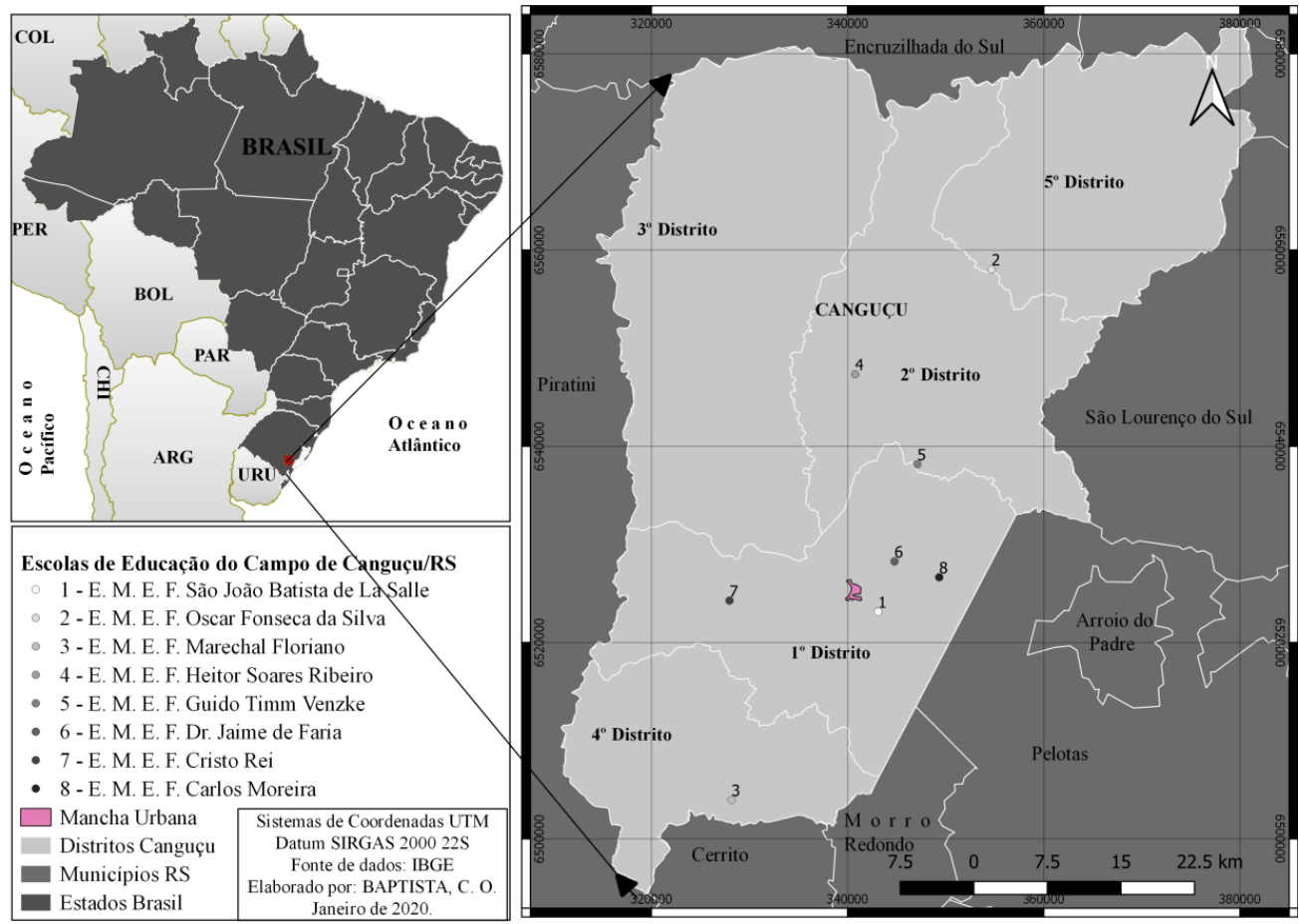

Fonte: Elaborado por BAPTISTA (2020).

Para que a escola se insira no Projeto, deverá ter, em primeiro lugar, infraestrutura que comporte todos os alunos em turno integral, como, por exemplo, refeitório amplo, quantidade de salas que comportem as demandas, cada professor deverá ter a sua sala, a chamada sala temática e ao invés do professor se dirigir as salas onde estão os alunos, são os alunos que vão para a sala temática ao encontro dos professores. O segundo crítério refere-se ao interesse da comunidade escolar e dos professores da escola, ou seja, a maioria dos pais ou responsáveis dos alunos e os professores devem estar de acordo com a inserção do Projeto, para isso, a escola realiza várias reuniões com a comunidade escolar e com os professores.

2.5. Perspectivas e limites do Projeto Educação do Campo de Canguçu/RS (EDUCCAN) e as mudanças no ensino de geografia

A partir do ano de 2018, todas as escolas que implementaram o Projeto EDUCCAN, passaram por significativas mudanças, as quais vão desde a estrutura física da escola até a forma didático-pedagógica de organizar, trabalhar e compreender a educação do campo. Objetiva-se uma educação de qualidade aos povos do campo para além das práticas tradicionais de ensino-

ParaOnde!?, Porto Alegre, v.14, n.1, p.31-54, 2020.http://seer.ufrgs.br/paraonde 
aprendizagem, levando ao desencadeamento de práticas agroecológicas e mudanças nos processos produtivos do campo.

Desta forma, as escolas passam a compreender que a educação do campo não busca somente oportunizar o acesso a educação, mas também procura enaltecer os conhecimentos das comunidades tradicionais a partir de seus saberes e práticas, de suas relações com a natureza e seus processos de produção, ou seja, constitui-se como uma educação voltada para a garantia do modo de vida do homem do campo. Essas mudanças, gradativamente, se consolidando nas escolas pesquisadas, como pode ser observado na fala dos diretores, a partir do Quadro 1.

\begin{tabular}{|c|c|}
\hline Diretor (a) & Mudancas \\
\hline Diretor D1 & $\begin{array}{l}\text { A principal foi a desacomodação das famílias, alunos e professores. } \\
\text { Em relação ao trabalho: ter um momento de planejamento semanal } \\
\text { de maneira coletiva; trabalhar a realidade na qual os alunos estão } \\
\text { inseridos; maior carga horária; as turmas terem salas temáticas de } \\
\text { uso exclusivo; maior socialização e adaptação dos alunos na } \\
\text { educação infantil e anos iniciais, além de valorizar financeiramente } \\
\text { os professores, pois atuam apenas em uma escola com carga } \\
\text { horária de } 40 \text { horas. }\end{array}$ \\
\hline Diretor D2 & $\begin{array}{l}\text { A principal mudança é de perspectiva de abordagem da realidade do } \\
\text { aluno, além de tê-lo em uma escola de turno integral, proporcionando } \\
\text { o aumento de sua carga horária e uma proposta de integração maior } \\
\text { com a família, pois, desenvolvemos projetos ligados a prática diária } \\
\text { de sua família usando um tempo de casa, criado através de uma } \\
\text { pedagogia de alternância casa/escola em um dia da semana, } \\
\text { construindo com o aluno uma visão positiva do meio onde vive sua } \\
\text { família e reconhecendo na comunidade onde está inserido o seu } \\
\text { lugar e através de uma pedagogia empreendedora buscando } \\
\text { alternativas de um futuro melhor. }\end{array}$ \\
\hline Diretor D3 & $\begin{array}{l}\text { Com o Projeto EDUCCAN os alunos estudam na modalidade de } \\
\text { Educacão Integral baseado na Pedagogia da Alternância. }\end{array}$ \\
\hline Diretora D4 & $\begin{array}{l}\text { Mudanças na organização da escola (horário do lanche, do almoço, } \\
\text { do transporte), mudanças no período de aula, nos dias trabalhados, } \\
\text { na aprendizagem dos alunos (trabalhos com projetos), ampliação da } \\
\text { carqa horária e tempo na escola. }\end{array}$ \\
\hline
\end{tabular}

Fonte: Pesquisa de campo, 2019.

O Projeto foi bem aceito pelos professores das escolas, pois possibilita o desenvolvimento de atividades diversificadas, com uma didática diferenciada, propiciando a aproximação entre alunos e professores, melhorando o aprendizado (D1, 2019). As mudanças mais significativas referenciadas pelos diretores são: desacomodação das famílias, alunos e professores; consideração da realidade dos alunos; escola de turno integral; adesão da Pedagogia da Alternância e o desenvolvimento de projetos (DIÁRIO DE CAMPO, 2019). As escolas passaram por grandes mudanças estruturais, as quais estão muito além da oferta do turno integral, motivo pelo qual é essencial que todo o grupo envolvido esteja comprometido.

$\mathrm{Na}$ visão das professoras, as principais mudanças se caracterizam pela: "organização do espaço físico da escola, horários das aulas, dinâmica de uso

ParaOnde!?, Porto Alegre, v.14, n.1, p.31-54, 2020.http://seer.ufrgs.br/paraonde 
das salas de aula a partir das salas temáticas, valorização da comunidade local e do espaço rural". Destacam, ainda, a importância do horário disponibilizado para a Construção Pedagógica do Aluno e a Construção Pedagógica do Professor (P1, P2, P3, 2019).

No que tange às disciplinas ministradas pelas depoentes, todas evidenciam que além da Geografia, ministram outras disciplinas, entre as quais estão: História, Agricultura e Administração Rural (AAR), Arte e Ética, Valores e Cidadania. Toda essa carga de disciplinas exige do professor uma formação transdisciplinar. Como as disciplinas das suas áreas de formação possuem carga horária baixa, ou seja, dois períodos semanais, do $6^{\circ}$ ao $9^{\circ}$ ano, o que soma oito períodos semanais, o professor que trabalha 40 horas semanais nas escolas que fazem parte do Projeto, tem um total de 25 períodos semanais e mais três períodos extracurriculares, isto é, o CPA. Com isso, para completar a carga horária acabam ministrando as demais disciplinas que não são da sua área de formação.

No Quadro 2, observa-se que das professoras que ministram a disciplina de Geografia, P1 e P3, possuem licenciatura em Geografia, e especialização em educação. P1 é mestra em educação e P3 em Geografia. A professora P2 é licenciada em História e possui pós-graduação (especialização). O tempo de docência das pesquisadas varia de dois a cinco anos.

\section{Quadros 2 - Dados gerais de identificação das professoras de geografia pesquisadas}

\begin{tabular}{cllc}
\hline Professoras & \multicolumn{1}{c}{ Formação } & Disciplinas Ministradas & $\begin{array}{c}\text { Tempo na } \\
\text { docência }\end{array}$ \\
\hline P1 & $\begin{array}{l}\text { Licenciatura em Geografia, } \\
\text { Especialização e Mestrado em } \\
\text { Educação. }\end{array}$ & $\begin{array}{l}\text { Geografia, História, Agricultura } \\
\text { e Administração Rural (AAR) e } \\
\text { Arte. }\end{array}$ & anos \\
P2 & $\begin{array}{l}\text { Licenciatura em História, História, Geografia e AAR. } \\
\text { Especialização em } \\
\text { Metodologias do Ensino de } \\
\text { História e Geografia. }\end{array}$ & 04 anos \\
& $\begin{array}{llll}\text { Licenciatura em Geografia, Geografia, História, Arte e Ética, } \\
\text { P3 especialização em Educação, valores e cidadania. } \\
\text { Mestrado em Geografia. }\end{array}$ & 05 anos \\
\hline
\end{tabular}

Fonte: Pesquisa de campo, 2019

Todas as professoras possuem carga horária semanal de 40 horas na mesma escola e residem atualmente no espaço urbano. Uma das professoras relatou que possui uma relação de identidade com o campo, tendo em vista que residiu durante 30 anos no espaço rural. Ela declara que somente mudou para o espaço urbano em decorrência do trabalho, começou a exercer a docência e o transporte que possibilita o acesso a escola em que leciona sai da área urbana a qual ficou distante da casa dos seus pais onde morava na época, tornando inviável sua permanência no espaço rural (DIÁRIO DE CAMPO, 2019).

ParaOnde!?, Porto Alegre, v.14, n.1, p.31-54, 2020.http://seer.ufrgs.br/paraonde 
Ao serem questionadas se a formação acadêmica foi suficiente no sentido de prepara-lás para atuarem na educação do campo, duas professoras ( $\mathrm{P} 1$ e P3) responderam que sim, pois durante a formação acadêmica tiveram contato com professores, disciplinas e livros que tratam sobre o assunto, assim como vivenciaram espaços e tempos formativos referentes à educação do campo. P1 (2019) ainda destaca que o título não encerra a formação, a docência exige busca permanente de subsídios para que o trabalho em sala de aula seja efetivo e contribua com a formação humana. A outra professora (P2, 2019), respondeu que sua formação não a preparou para atuar no campo. Contudo, evidencia que uma iniciativa importante da Secretaria Municipal de Educação, Esporte e Cultura é o curso de formação para os professores das escolas do campo em parceria com a Empresa de Assistência Técnica e Extensão Rural (EMATER) e o Centro de Treinamento de Canguçu (CETAC).

Apesar de duas professoras salientarem que receberam formação nos cursos de Graduação, sabe-se que ainda são poucos os cursos de Licenciatura em Geografia e História, especificamente, que possuem em seus currículos disciplinas que contemplam e aprofundam as especificidades da Educação do Campo. Os futuros professores acabam, muitas vezes, se aproximando das escolas do campo através de seus estágios curriculares supervisionados ou na elaboração do Trabalho de Conclusão de Curso, onde passam a ter contato com leituras que discutem a temática. Existe uma carência de profissionais disponíveis com formação em Educação do Campo, afirmações que são corroboradas pelo aumento da oferta de Cursos de Licenciatura em Educação do Campo, inclusive, no estado do Rio Grande do Sul, os quais ocorrem na modalidade presencial e na educação a distância, havendo um polo da Educação a Distância (EaD) em São Lourenço do Sul/RS, município limítrofe de Canguçu, com a oferta do Curso de Licenciatura em Educação do Campo com formação na área das Ciências Humanas.

Em relação às perspectivas e limites do Projeto Educação do Campo de Canguçu, os diretores destacam que:

\begin{abstract}
Perspectivas: melhoria na preparação dos profissionais para que realmente atendam as possibilidades que a proposta pode trazer no seu desenvolvimento, especialmente, desenvolver as habilidades e competências necessárias para atender a demanda de cada educando. O princípio da proposta de educação do campo pode ser replicado em qualquer espaço, pois, reconhece os valores locais, da comunidade e das famílias e trabalha a cooperação, a união, a ética e o desenvolvimento sustentável. Melhoria na educação principalmente para aquele aluno que pretende continuar no espaço rural. Se houver empenho e dedicação do grupo de trabalho, as perspectivas são boas, pois o objetivo principal é a qualidade do ensino, reconhecimento do espaço rural, diminuição da evasão escolar e novas práticas pedagógicas (D1, D2, D3 e D4, 2019).
\end{abstract}

Limites: apenas um diretor (D1) respondeu como limite do projeto, que o mesmo está nas pessoas que não conhecem a realidade e muitas vezes são as que tomam as decisões. 
Por sua vez, as professoras, quando perguntadas sobre as perspectivas e limites do Projeto relatam que:

\begin{abstract}
Perspectivas: a possibilidade do desenvolvimento de estratégias pedagógicas que propiciam o fortalecimento dos laços entre alunos e a escola, contribuir com a ressignificação da identidade rural, a valorização do espaço rural e as particularidades de cada localidade (P1, P2 e P3, 2019).

Limites: a questão da desacomodação, pouco investimento na parte tecnológica. Também a formação de professores e de toda a rede para trabalhar o tema, não ter objetivos claros do que se quer atingir, além de pouco ou nenhum embasamento teórico da maioria dos envolvidos, assim como um descompasso das atividades, são vários projetos e atividades extraclasses que fazem com que os conteúdos e a educação do campo fiquem em segundo plano (P1, P2 e P3, 2019).
\end{abstract}

A partir dos apontamentos das pesquisadas é perceptível a consciência da necessidade de utilizar distintas estratégias de ensino-aprendizagem, as perspectivas do que devem realizar estão bem claras, o que significa que elas possuem domínio das metas do Projeto EDUCCAN. Contudo, os limites são compreendidos como entraves, as dificuldades que enfrentam cotidianamente para colocar em prática suas ações.

Neste ínterim, convém lembrar que o Projeto está em sua fase inicial, período caracterizado pelos aprendizados, ajustes e mudanças (D1, D2, D3). Não existe, até o presente momento, um modelo pronto que possa ser reproduzido nas escolas do campo. Cada espaço precisa elaborar seu PPP e adequar suas ações de acordo com as características socioterritoriais da comunidade em que a escola está inserida, tendo em vista que dentro de um mesmo espaço as relações podem se estabelecer de distintas formas. Nesse processo, é necessário, segundo Fernandes (2005, p.28), compreender que:

\begin{abstract}
[...] as relações sociais transformam o espaço em território e vice e versa, sendo o espaço um a priori e o território um a posteriori. $\mathrm{O}$ espaço é perene e o território é intermitente [...] o espaço e o território são fundamentais para a realização das relações sociais, e produzem continuamente espaços e territórios de formas contraditórias, solidárias e conflitivas, esses vínculos são indissociáveis.
\end{abstract}

Ao serem abordadas sobre como trabalham nas escolas o ensino da Geografia e as metodologias utilizadas, P1, P2 e P3 (2019), destacam que utilizam "mapas, gráficos, maquetes, sala de aula invertida, apostilas, vídeos, filmes, exemplos da realidade do aluno e sua ligação entre os conteúdos e as vivências de cada turma". Ainda, salientam que suas metodologias e práticas são definidas semanalmente com a realização dos planejamentos, dos projetos, pesquisas e atividades vinculados ao Projeto a partir da Construção Pedagógica do Professor (CPP).

A partir do contexto relatado, visualiza-se que o momento da CPP, que acontece todas as segundas-feira é essencial, tendo em vista que a partir deles os professores realizam conjuntamente o planejamento, esclarecem dúvidas e organizam as atividades que serão desenvolvidas no decorrer da semana.

Especificamente na disciplina de Geografia, as depoentes P1, P2, P3 (2019), relataram que buscam formas de potencializar a construção do

ParaOnde!?, Porto Alegre, v.14, n.1, p.31-54, 2020.http://seer.ufrgs.br/paraonde 
conhecimento geográfico. A prática de vincular o conteúdo à realidade dos alunos possibilita a construção de conhecimentos dotados de significados, quer dizer, parte-se de um conhecimento prévio, faz-se uma relação com o conhecimento novo tomando como referência o espaço de vivência do aluno, esse processo permite elaborar uma relação processual entre os conhecimentos.

Quanto às mudanças ocorridas no processo de ensino-aprendizagem a partir da implantação do projeto, P1 (2019), elenca que entre as mais visíveis estão:

[...] relação mais direta dos alunos com as informações, interação com as mídias, compreensão de conhecimento e pesquisa, os alunos estão mais motivados e mobilizados em sala de aula, desenvolvendo autonomia nas expressões escritas, orais e artísticas.

Vale ressaltar que as escolas estão utilizando com maior intensidade as tecnologias de comunicação e informação. Todas as professoras pesquisadas salientam que as aulas de Geografia se tornaram mais atrativas aos alunos e que estas mudanças estão ligadas a sala temática que foi implantada na escola, onde há disponibilidade de materiais como: mapas, livros, globo terrestre, entre outros, que auxiliam o processo de ensino-aprendizagem (DIÁRIO DE CAMPO, 2019). A partir da sala temática, os professores podem desenvolver diversas atividades vinculando teoria e práticas, desenvolvendo habilidades geográficas que permitam ao estudante compreender a totalidade da realidade em que está inserido, bem como, seu papel perante esta sociedade.

Com relação às formas de como trabalham a Geografia na Construção Pedagógica do Aluno, a partir do que as professoras responderam nos questionários, percebemos que elas utilizam distintas técnicas, didáticas e metodologias de ensino, como pode ser obervado nas falas das depoentes:

O ponto de partida dos assuntos e temas são aspectos próximos dos alunos, nesse processo amplia-se a análise do fenômeno em estudo para escalas mais amplas. A proposição é que o aluno consiga estabelecer relações entre diferentes espaços e tempos (P1, 2019).

Trabalho com a construção de mapas da comunidade, como o caminho percorrido até a escola (mapa mental), gráficos sobre os produtos comercializados e produzidos pelos agricultores, a geografia local, entre outros (P2, 2019).

Conforme o tema escolhido e atividade que será realizada coloco as contribuições da ciência geográfica no sentido de fazer a análise geográfica $(P 3,2019)$.

Outro elemento importante a se destacar, é que a maioria dos alunos são filhos de agricultores familiares, o que facilita o período da alternância e a implementação dos Projetos e das práticas nas propriedades. Também estão presentes filhos de agricultores não familiares, empregados rurais e empregados urbanos. Independente da condição, todos devem desenvolver as atividades práticas em suas residências.

Um exemplo de atividade prática é o cultivo de alimentos para o consumo familiar. Aqueles alunos que residem no espaço urbano geralmente possuem

ParaOnde!?, Porto Alegre, v.14, n.1, p.31-54, 2020.http://seer.ufrgs.br/paraonde 
um espaço para a produção de alimentos como as hortas. Convém destacar que cada escola está organizada de uma maneira e possui autonomia na forma de acompanhar o desenvolvimento das atividades práticas. Uma das escolas pesquisadas salienta que, neste processo, são os professores que se deslocam até as propriedades das famílias dos alunos para verificarem as práticas que estão sendo desenvolvidas pelos alunos.

Apesar da relevância do Projeto em questão e de seu potencial na construção de uma educação emancipatória, P1, P2 e P3 (2019), relatam que ainda possuem dificuldades principalmente no acesso a materiais adequados para a preparação dos projetos e das aulas. Em relação à Construção Pedagógica do Professor evidenciam estar atendendo em partes as demandas de sala de aula, já que cabe ao professor organizar as atividades e assuntos que irá desenvolver (DIÁRIO DE CAMPO, 2019).

\section{Considerações finais}

A educação do campo surge com a necessidade de pensar a educação para as populações rurais, nasce do resultado da luta dos trabalhadores rurais pelo acesso a terra em contraponto a grandes latifundiários.

A partir da pesquisa, evidencia-se que educação do campo não busca somente oportunizar o acesso a educação, mas também procura enaltecer os conhecimentos das comunidades tradicionais, entre os quais estão os agricultores familiares a partir de seus saberes e práticas, de suas relações com a natureza. Esses conhecimentos são potencializados no momento em que $o$ aluno se encontra realizando a prática na propriedade, período caracterizado pela alternância.

Os resultados revelam também que a escola do campo não se consolida pela simples transposição dos modelos educacionais urbanos para o espaço rural. É importante que novos Projetos Políticos Pedagógicos se consolidem para que os alunos do campo tenham uma formação que os aproxime da sua realidade.

O Projeto Educação do Campo de Canguçu/RS (EDUCCAN) está voltado para o meio onde os alunos vivem; busca valorizar os professores, possibilitando que todos trabalham em apenas uma escola, com carga horária de 40 horas semanais, condição considerada positiva para professores da educação básica.

Frente às respostas das professoras pesquisadas, verificou-se que elas contextualizam os conteúdos da disciplina de Geografia às vivências dos alunos, procurando estabelecer uma aprendizagem significativa, ainda que o período caracterizado pela Construção Pedagógica do Aluno (CPA) possibilite o desenvolvimento de projetos que tratam sobre temas geográficos ligados à realidade dos alunos, o que por sua vez, potencializa a aprendizagem.

As professoras em questão foram colocadas à frente de uma nova realidade e estão buscando se (re) construir didaticamente, pedagogicamente e teoricamente, enquanto educadoras do campo, cumprindo a tarefa de relacionar os conteúdos ao contexto do campo vivido pelos alunos.

ParaOnde!?, Porto Alegre, v.14, n.1, p.31-54, 2020.http://seer.ufrgs.br/paraonde 
As principais mudanças destacadas se referem à rotina escolar com a inserção do turno integral, a criação de salas temáticas, a implantação de períodos destinados a Construção Pedagógica do Aluno (CPA), a Construção Pedagógica do Professor (CPP), a valorização da comunidade local e do espaço rural.

As perspectivas do Projeto são positivas, porém, existe ainda a necessidade de melhorias na capacitação dos profissionais da educação, para que estes possam desenvolver e atingir plenamente aos objetivos propostos. A falta de embasamento teórico e de materiais didáticos para a realidade do campo dificultam as ações dos professores, o que demonstra que algumas das decisões são tomadas de forma verticalizada, sem o conhecimento da realidade.

Apesar da crescente demanda de licenciados em Educação do Campo e da oferta de cursos universitários com formação nesta área, ainda existem muitos obstáculos para inserção destes profissionais no mercado de trabalho. Os Estados e prefeituras na abertura de concursos ou processos seletivos, na maioria das vezes, destinam poucas vagas para esses profissionais, quando lembram deles. O que se caracteriza, no entanto, como uma contradição.

Por fim, no ano de 2020, ao término da escrita deste artigo, nos foi repassado que mais duas escolas aderiram ao EDUCCAN, sendo a E.M.E.F. Gonçalves Dias, localizada no Rincão dos Marques - $4^{\circ}$ distrito e a E.M.E.F. Joaquim Nabuco, localizada na Santa Clara - 1ำ distrito. Com isso, 10 escolas fazem parte do Projeto. Salienta-se que outras pesquisas de diversas áreas do conhecimento podem ser realizadas, para assim, demonstrar quais mudanças que vão ocorrer e a importância desse recente Projeto que vem sendo desenvolvido no município de Canguçu/RS.

\section{Referências:}

AFUBRA, Associação dos Fumicultores do Brasil. Contato 2018. Disponível em: <afubra.com. br>. Acesso em: 15 Dez. 2018.

BRASIL. Resolução CNE/CEB № 1, de 3 de abril de 2002. Institui diretrizes operacionais para a educação básica das escolas do campo. Brasília. Disponível em: <http://portal.mec.gov.br/cne/arquivos/pdf/CEB012002.pdf>. Acesso em: 06 dez. 2019.

BRASIL. Resolução № 2, de 28 de Abril de 2008. Diretrizes complementares, normas e princípios para o desenvolvimento de políticas públicas de atendimento da Educação Básica do Campo, Brasília, 2008.

CALDART, Roseli Salete. Por uma Educação do Campo: traços de uma identidade em construção. In: ARROYO, Miguel Gonzalez; CALDART, Roseli Salete; MOLINA, Mônica Castagna (Orgs.). Por Uma Educação do Campo. Petrópolis-RJ: Vozes, 2004.

Por uma educação do campo: traços de uma identidade em construção. In: ARROYO, Miguel Gonzalez; CALDART, Roseli Salete; MOLINA, Mônica Castagna (Orgs.). Por uma Educação do Campo. 5 Ed.

ParaOnde!?, Porto Alegre, v.14, n.1, p.31-54, 2020.http://seer.ufrgs.br/paraonde 
Petrópolis/RJ: Vozes, 2011, p. 147-158.

CALLAI, Helena. Estudar o lugar para compreender o mundo. In: CASTROGIOVANNI, Antônio Carlos (Org.). Ensino de geografia: práticas e textualizações no cotidiano. Porto Alegre: Mediação, 2000.

COPATTI, Carina; CALLAI, Helena Copetti. O ensino de geografia em educação do campo e o livro didático. Contexto \& Educação. Unijuí, v. 33, p. 222-247, 2018.

DAVID, Cesar de. O ensino de geografia nas escolas do campo: subsídios para uma prática integradora. In: MATOS, Kelma Socorro Alves Lopes de; WIZNIEWSKY Carmen Rejane Flores; MEURER, Ane Carine; DAVID, Cesar De (Orgs.). Experiências e diálogos em educação do campo. 1 Ed. Fortaleza: Edições UFC, 2010, p. 39-49.

FERNANDES, Bernardo. Mançano. Movimentos socioterritoriais e movimentos socioespaciais: contribuição teórica para uma leitura geográfica dos movimentos sociais. REVISTA NERA - Presidente Prudente, ano 8, №. 6, p. 24-34, 2005.

Diretrizes de uma caminhada. In: ARROYO, Miguel Gonzalez; CALDART, Roseli Salete; MOLINA, Mônica Castagna (Orgs.). Por uma Educação do Campo. 5 Ed. Petrópolis/RJ: Vozes, 2011, p. 133-145.

Educação do Campo: História, Práticas e Desafios. Entrevista com Bernardo Mançano Fernandes, por Graziela Rinaldi da Rosa. Reflexão \& Ação, Vol. 22, № 2, p. 481-87, 2014.

FERNANDES, Bernardo Mançano; CERIOLI, Paulo Ricardo; CALDART, Roseli Salete. Primeira Conferência Nacional "Por Uma Educação do Campo". In: ARROYO, Miguel Gonzalez; CALDART, Roseli Salete; MOLINA, Mônica Castagna (Orgs.). Por uma Educação do Campo. 5 Ed. Petrópolis/RJ: Vozes, 2011, p. 19-63.

GOVERNO DO ESTADO DO RIO GRANDE DO SUL. Resolução N. 342 de 11 de abril de 2018. Consolida as Diretrizes Curriculares da Educação Básica nas Escolas do Campo e estabelece condições para a sua oferta no Sistema Estadual de Ensino. Disponível em: < http://www.ceed.rs.gov.br>. Acesso em: 20 de dez. 2019.

IBGE. Instituto Brasileiro de Geografia e Estatística. Censo Demográfico 2010. Disponível em: <http://cidades.ibge.gov.br>. Acesso em: 15 Set. 2019.

JESUS, José Novais de. A pedagogia da alternância e o debate da educação no/do campo no estado de Goiás. Revista NERA. Presidente Prudente - SP, v. 18, p. 07-20, 2011.

MEDEIROS, Rosa Maria Vieira; FOGAÇA, Jaime. Educação do campo, desafios e perspectivas. In: WIZNIEWSKY, Carmen Rejane Flores; MOURAD, Leonice Aparecida de Fátima Alves (Orgs.). Educação, memória e resistência popular na formação social da América Latina. 1 Ed. Porto Alegre: Evangraf, v. 1, p. 137-144, 2016.

MOLINA, Mônica Castagna; FREITAS, Helena Célia de Abreu. Avanços e

ParaOnde!?, Porto Alegre, v.14, n.1, p.31-54, 2020.http://seer.ufrgs.br/paraonde 
desafios na construção da educação do campo. Em Aberto, Brasília, v. 24, n. 85 , p. 17-31, 2011.

MOLINA, Mônica Castagna; Rocha, Isabel Antunes. A educação do campo: história, práticas e desafios no âmbito das políticas de formação de educadores - reflexões sobre o Pronera e o Procampo. Revista Reflexão e Ação, Santa Cruz do Sul, v.22, n.2, p.220-253, 2014.

OLIVEIRA, Alexandra Maria. Campesinato, ensino de geografia e escolas do campo: o conhecimento geográfico como um saber em conjunto. GEOUSP Espaço e Tempo. São Paulo, N. 30, p. 62-75, 2011.

PREFEITURA MUNICIPAL DE CANGUÇU. Regimento EDUCCAN: Educação do Campo de Canguçu/RS, 2019.

SILVA, Noemí Muller Iven da. O comportamento sucessório na agricultura familiar de Canguçu/RS. 2015. 149f. Dissertação (Mestrado em Geografia) Universidade Federal do Rio Grande, Rio Grande, 2015.

WIZNIEWSKY, Carmen Rejane Flores. A contribuição da geografia na construção da educação do campo. In: MATOS, Kelma Socorro Alves Lopes de; WIZNIEWSKY Carmen Rejane Flores; MEURER, Ane Carine; DAVID, Cesar De (Orgs.). Experiências e diálogos em educação do campo. 1 Ed. Fortaleza: Edições UFC, 2010, p. 27-38. 